\title{
Kanowna Belle - evolution of seismicity with increasing depth in an ageing mine
}

\author{
R. Varden Barrick Kanowna Ltd, Australia \\ H. Esterhuizen Barrick Kanowna Ltd, Australia
}

\section{Abstract}

Kanowna Belle went underground from the open pit in 1996. At the start of 2000 the decline had reached $950 \mathrm{~m}$ below surface and stoping was down to $740 \mathrm{~m}$. Seismicity was starting to occur and by May $2000 \mathrm{a}$ seismic system had been commissioned. Since then, seismicity has played an increasing role in risk management of the mine, both in respect to safety and production. Seismic events with increased damage potential only started to occur mainly below 970 m depth (below C-block). The increase in seismic risk has lead to the development and implementation of the Garford yielding bolt, the development of seismic management systems and the adaptation of the mining method and sequencing. With increasing depth and seismicity, development of the lower E-block the mine is now moving into a new environment where new support systems and seismic control systems are being developed and implemented. This paper highlights the need for long term planning strategies, good quality seismic and geology data collection, analysis and recognition of high risk zones and subsequent management systems that involve planning, analysis, support, exclusion zones and education/communication of the workforce.

\section{$1 \quad$ Introduction}

\section{1 Location}

The Kanowna Belle Gold Mine, Figure 1, is located $18 \mathrm{~km} \mathrm{NE}$ of Kalgoorlie and $2 \mathrm{~km}$ west of the historic gold mining centre of Kanowna, Western Australia.

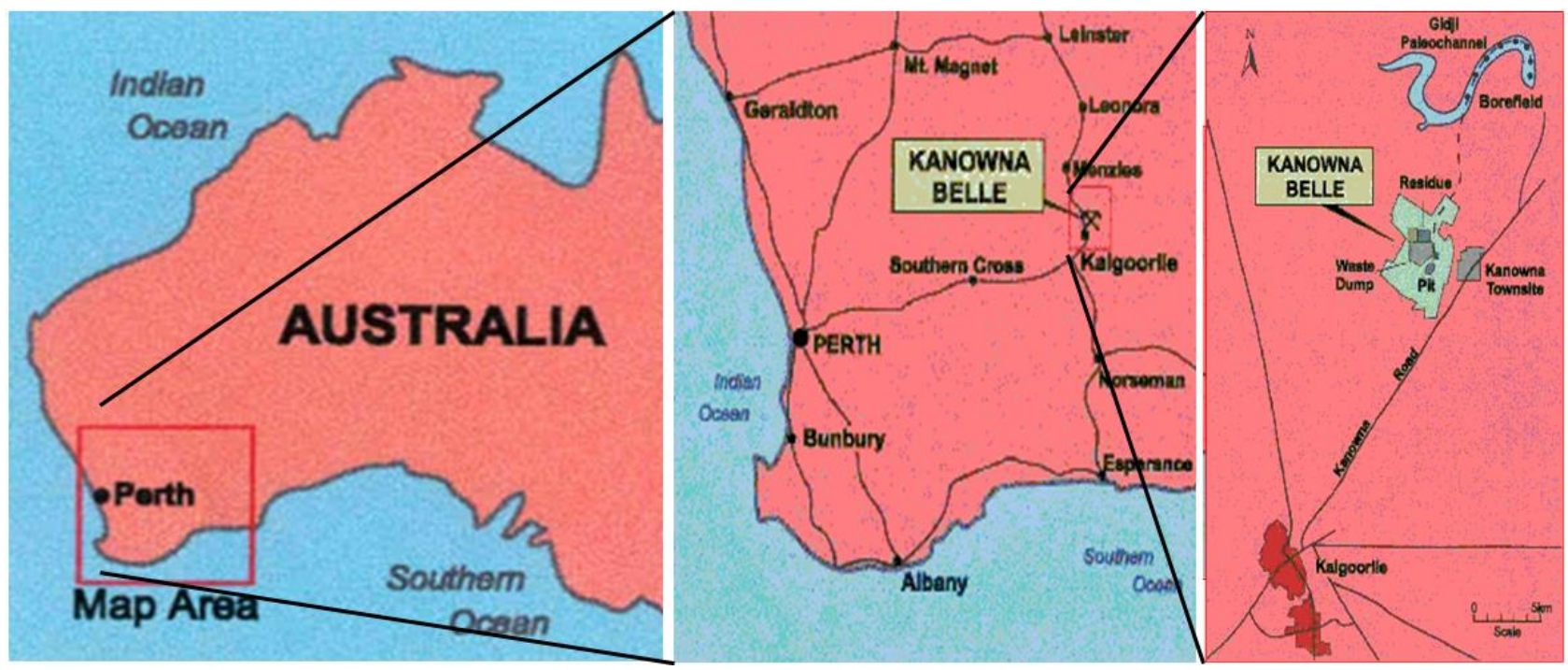

Figure 1 Location map of Kanowna Belle Mine

\section{2 Geology}

The Kanowna Belle deposit is hosted by sedimentary volcaniclastic and conglomeratic rocks, which are separated into hangingwall and footwall sequences by a major, steeply SSE dipping zone of structural 
disruption. The orebody strikes east-west, varies from 5-50 $\mathrm{m}$ in width, with an average dip of $65^{\circ}$. The main structural feature in the deposit is the Fitzroy fault, which varies in width and dip. It is an undulating structural zone dipping on average $65^{\circ}$ and is gouge filled in some areas, but is mainly a zone of highly broken rock. The fault forms the footwall in A, B and C-block and the hangingwall of the ore zone in D- and E-block. The Fitzroy fault is then encompassed by the footwall and hanging wall shear zones.

A number of splay structures off the fault exist. These are sub-parallel to the fault and occur either side of the fault. They are substantial in length and down dip strike.

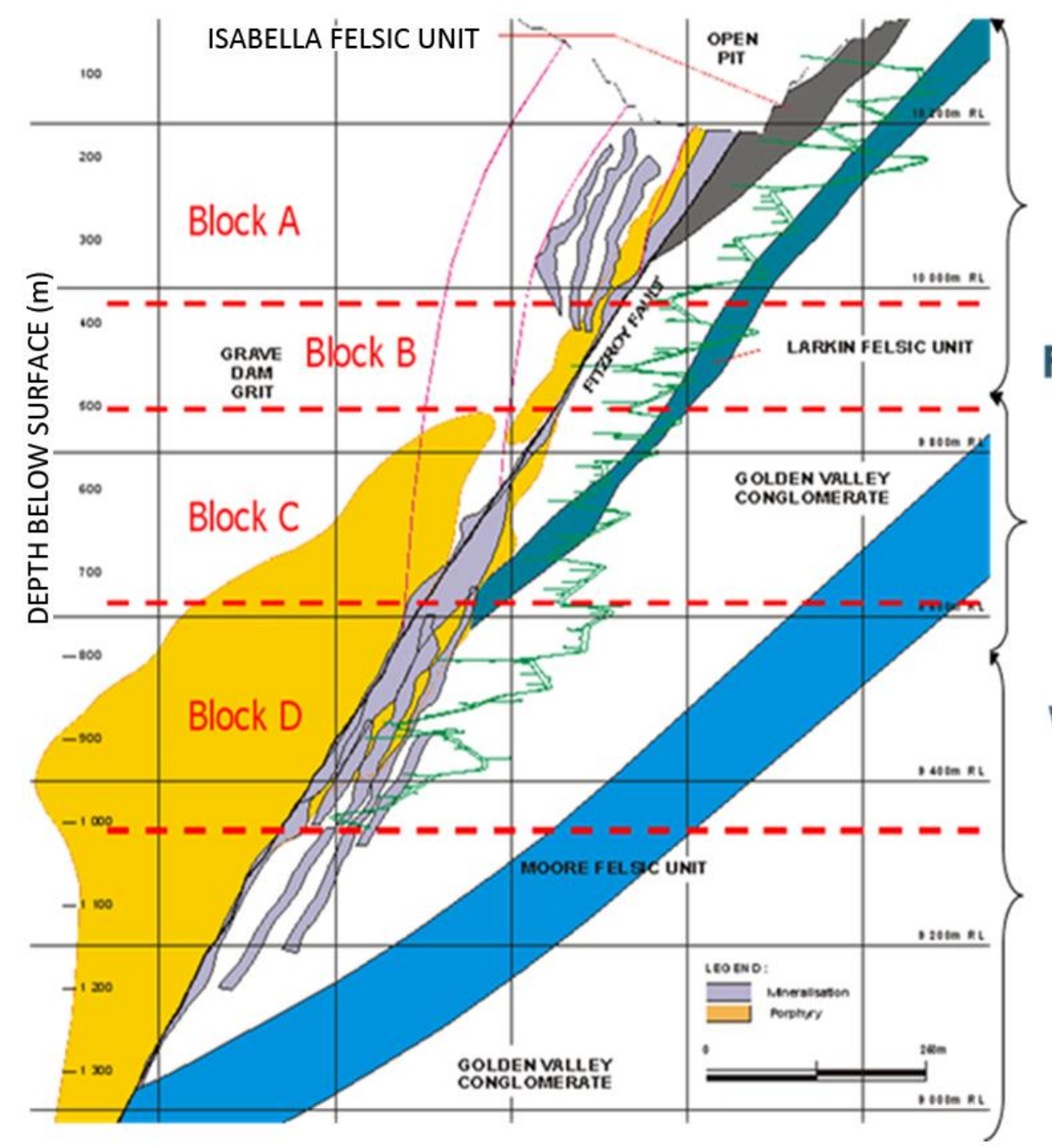

\section{Upper Mine} HW Lodes Fitzroy Fault on orebody FW Central Mine Fitzroy Fault contained within orebody Lower Mine

FW Lodes Fitzroy Fault on orebody HW

Figure 2 Kanowna Belle generalised geology section

\section{3 Mining sequence}

The mine has been divided into five mining blocks: A-block - mined out, B and C-blocks - mature mining areas with some scattered stopes still to be mined, D - currently stoping, E - started stoping and development in progress. The mining method is long-hole open stoping, with $30 \mathrm{~m}$ sublevels. Sequencing (Figure 3 ) is centre out bottom up with paste fill. Mining is distributed over several mining fronts and depths.

\section{4 Rock mass characteristics}

The rock mass has an intact rock strength measured between 90 to $140 \mathrm{MPa}$, with the Fitzroy fault having a UCS of $40 \mathrm{MPa}$. In general the rock mass can be described to be fair to very good, with the exception of the Fitzroy fault being very poor. The rock mass is, however, intensely faulted, with regular intersections of smaller faults and fault sets. The strength of the fault contacts, their extent and orientation in relation to mining has an influence on the seismic response of the rock mass. 


\subsection{Stress characteristics}

The major principal stress at $1,000 \mathrm{~m}$ is $75 \mathrm{MPa}$ and is subhorizontal $(124 / 06)$ at a ratio of 1:2.3 (V:H). This high compressive ratio causes stresses to concentrate in the backs and floors of development. It has been observed that with increasing depth the depth of fracturing in the backs has also increased, Figure 4.

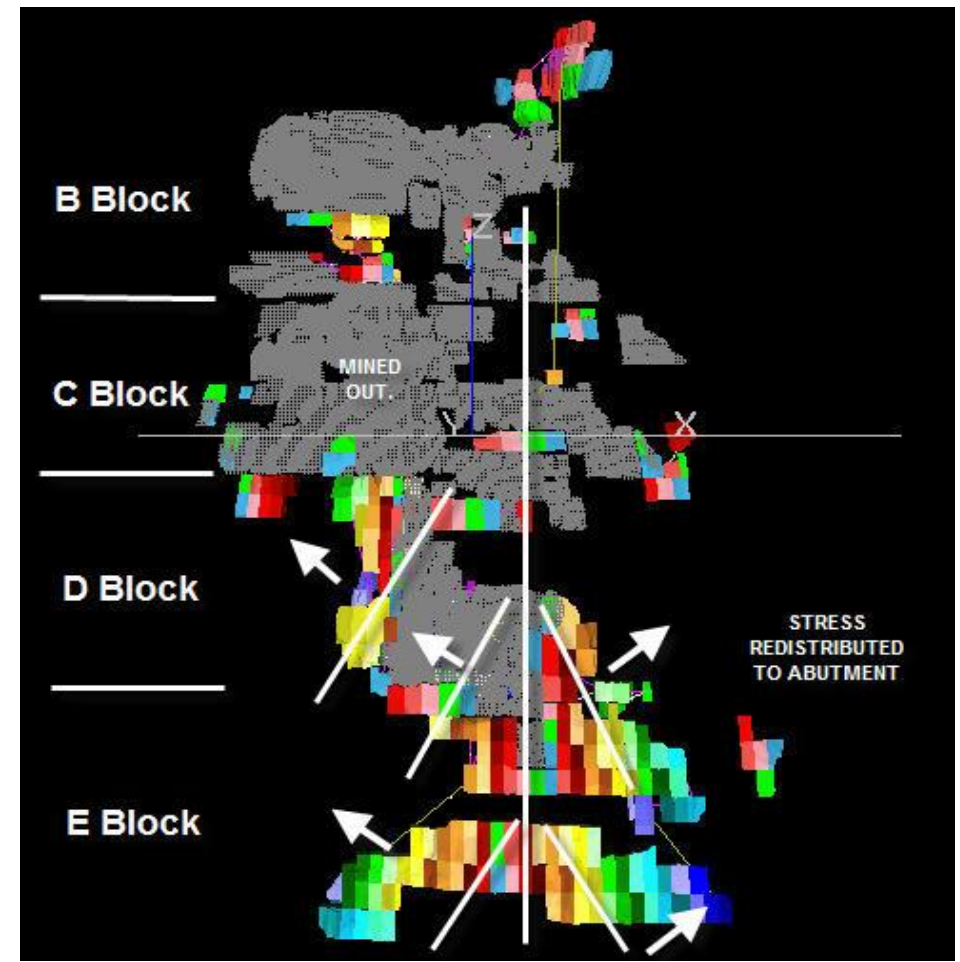

Figure 3 Mining sequence

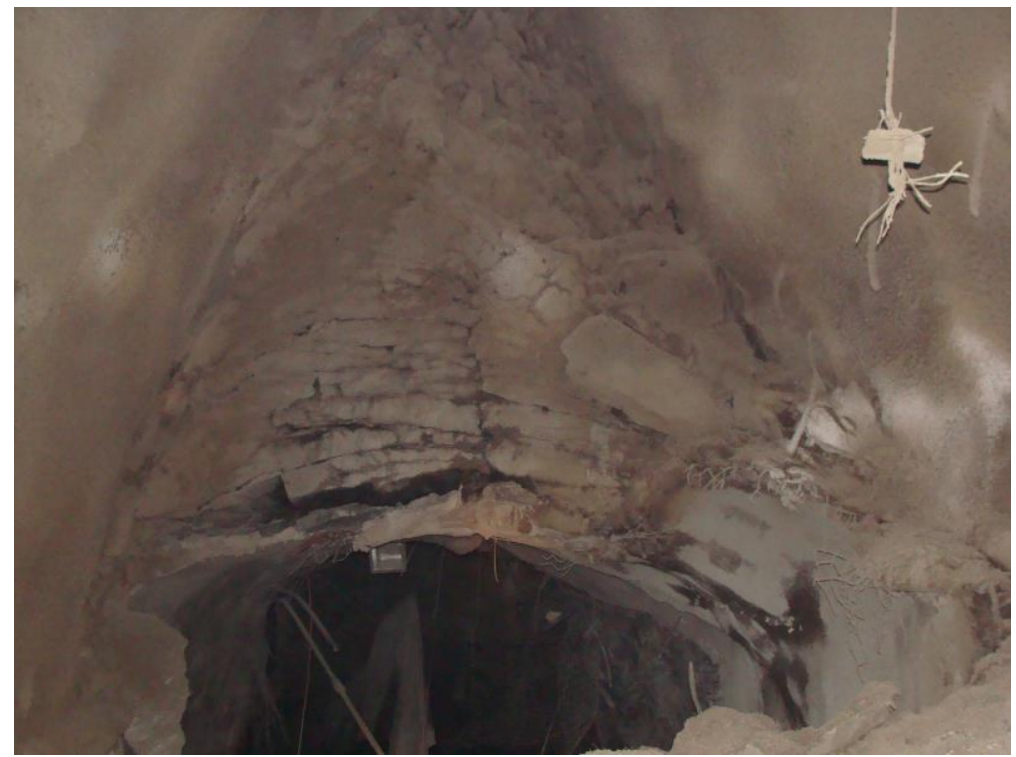

Figure 4 Increased depth of fracturing

\section{Seismic system}

Kanowna Belle uses the ISS (IMS) seismic system. The system has been built up over time since May 2000, with around 50 sensors being installed; Figure 5 shows a schematic of the system. The sensors are a mixture of accelerometers and geophones, both uniaxial and triaxial. The seismic server is underground which allows for data to be collected even if communications are down between underground and surface. 
This system also allows for three backs ups: one underground, one on the surface seismic computer, and one with IMS. Processing of data is done by IMS on 24 hours a day basis. IMS also provides a weekly and monthly report summarising the seismicity and system health.

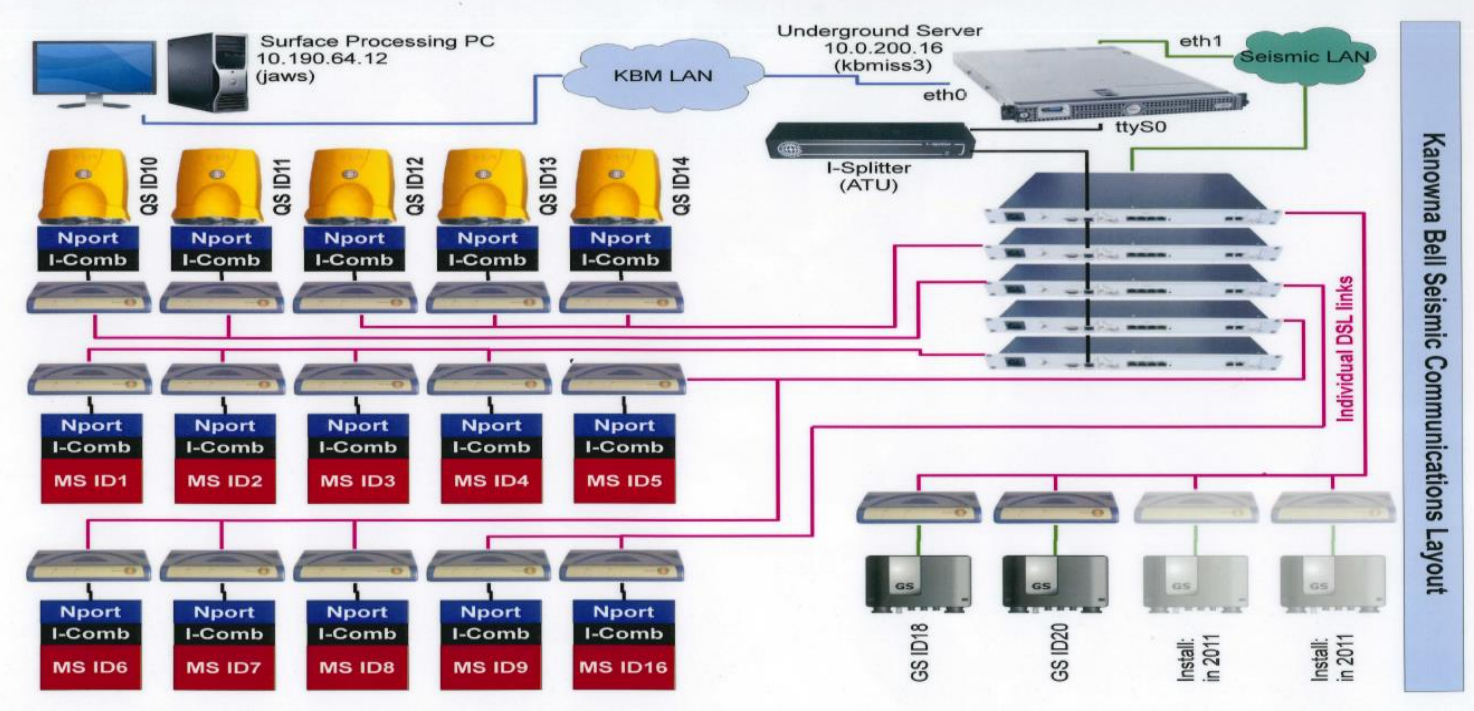

Figure 5 Seismic system schematic

Onsite seismic analysis is done with JDi and MS-RAP software packages. These are used for pro-active identification and management of areas with potential seismic risk. Examples are time-history analysis of several parameters for specific areas of the mine, and seismic risk mapping and reporting.

\section{Seismic evolution}

The frequency of occurrence of larger magnitude seismic events at Kanowna Belle, as with other Western Australian mines, has increased with depth (Figure 6).

\section{Seismic History for larger events $\left(M_{L}>1.2\right)$}

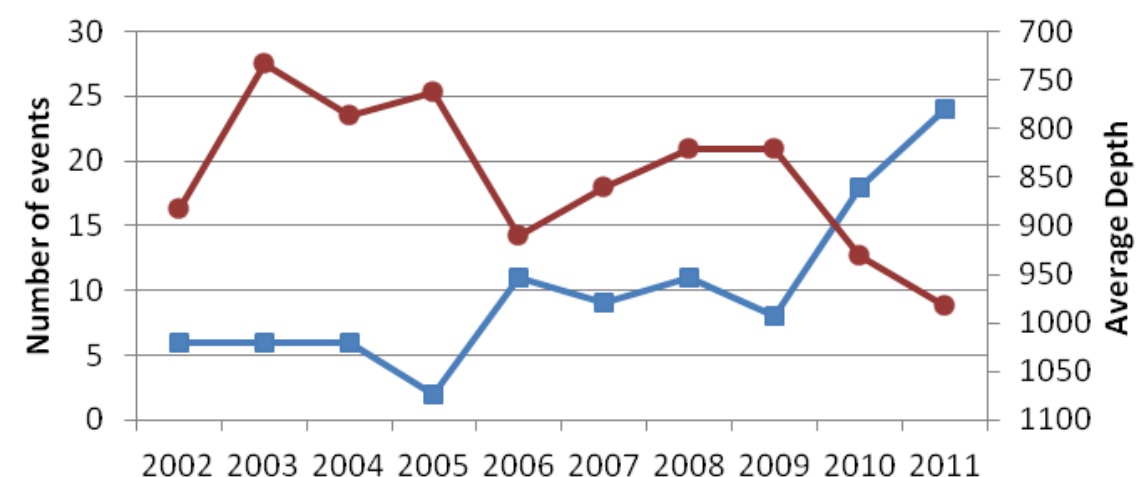

- Number of events $>1.2 \mathrm{ML} \longrightarrow$ Average Depth

Figure 6 Migration of large $(>1.2 \mathrm{ML})$ seismic events to deeper levels as mining advance deeper

The number of larger events per year has gradually increased with mining depth until the present. Since 2010 the location of mining activity has become more focused on the lower levels, especially D-block and Upper E-block. At these in depths, the associated stress levels, and the increased volume mined have all contributed to an increase in the number of events $>1.2 \mathrm{M}$. Another characteristic of the changing seismic behaviour is that event locations are not necessarily directly related to mining activity anymore. Larger events can occur in isolation away from active mining areas, especially where adverse faults are present in stressed abutments or pillars. 
With each large seismic event an investigation is carried out. A detailed analysis and review of what happened is undertaken, and where needed further improvements are made to systems and procedures. Recommendations for remedial work are issued and actions implemented to prevent/control similar occurrences. These controls may include changes to support systems, such as the introduction of dynamic support and changes in planning rules. Moving the hanging wall drive away from the Fitzroy fault and cross cutting fault intersections is one example of actions implemented.

The following section provides more details on the behaviour per mining block $(A=$ upper elevation, $\mathrm{E}=$ deeper elevation).

\section{1 A to C-block}

A-block and Troy commenced mining in 1996 from a depth of $140 \mathrm{~m}$ at the base of the pit to $375 \mathrm{~m}$, (9985RL). It is characterised by large open stopes, typically around $180,000 \mathrm{t}$ up to $480,000 \mathrm{t}$ that were mined in a primary secondary fashion. Backfilling was cemented aggregate fill (CAF) and waste fill for the secondary stopes. Seismicity in A-block, Figure 7 , accounts for $26 \%$ of the total activity with seven larger events and minor damage occurring. As a result of seismicity at shallow depths, pro-active changes were undertaken to minimise seismicity going forward.

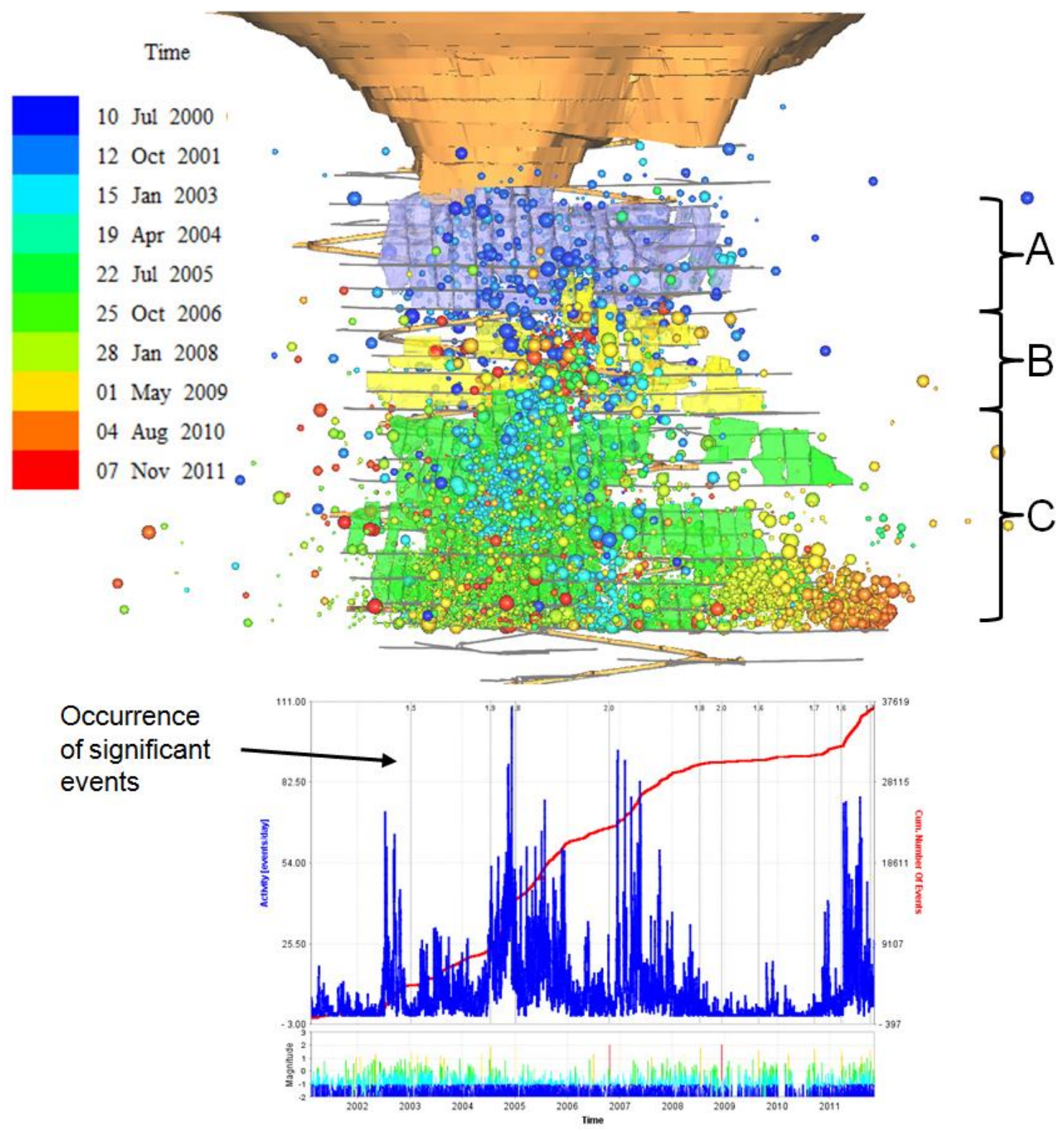

Figure 7 Seismicity in A to C-block 
B-block was partly mined in the late 1990s. B-block extends from $375 \mathrm{~m}$ to $500 \mathrm{~m}$, (9860RL), and is characterised by narrower, lower grade stopes. As a result of changes, these stopes were mined from the centre out with CAF for a period of time before the mine changed to paste fill. Initial seismic reaction to induced stresses from the method change was relatively good, but has deteriorated with recent mining where remnant pillars previously left due to low grade are now subjected to increased induced stress.

C-block, from $500 \mathrm{~m}$ to $740 \mathrm{~m}$, (9620RL) started production in mid 2000 and is still in production today, with the most recent activity the mining of stopes in the HW of the Fitzroy fault. C-block stopes are typically $20 \mathrm{~m}$ along strike, $8-12 \mathrm{~m}$ in width and $30 \mathrm{~m}$ in height; tonnages vary from 15,000 to 88,000 tonnes. Increased awareness to potential seismicity show the change in sequence to bottom up, centre out with paste fill. Seismic activity has been relatively low, but continuous, with the largest event a $1.8 \mathrm{M}_{\mathrm{L}}$ and 5 damaging events. During this period, pro-active seismic risk management saw the implementation of shotcreting on a larger scale.

\section{2 D-block}

D-block started in September 2002 from $740 \mathrm{~m}$ to 1,010 m (9350 RL). This block saw the start of mining in areas of elevated stress levels due to the increasing mining depth and relatively high in situ stress levels. Also the Fitzroy fault now forms the HW of the orebody. Stopes are typically $20 \mathrm{~m}$ along strike and 30 to $60 \mathrm{~m}$ high. The ore thickness is up to $60 \mathrm{~m}$ and this has resulted in stopes being divided into panels from the $\mathrm{HW}$ to FW. In general, the rock mass conditions and rock mass reaction to mining stresses have deteriorated compared to the upper blocks. It has also been observed that structural interaction is increasing with a number of new cross cutting faults being identified. An increase in seismic event occurrence was already experienced during the development phase of this block; sometimes with associated damage. This further progressed into the stoping phase.

This increase in activity with depth was anticipated and several measures were introduced to manage this. Some of the seismic control systems introduced at that time included:

- The development of stoping rules, implementation of a mine wide seismic system and increased ground support capacity. It was recognised that dynamic support would be required as one of the main controls. In 2005 a dynamic ground support selection and design project commenced with implementation in 2007 of the Garford Yielding Bolt (Varden et al., 2008). In-cycle fibrecrete in ore drives and other critical areas was also introduced.

- The first significant damaging event in D-block occurred on the 1st April 2002; it occurred during the development of the $9440 \mathrm{HW}$ drive. The first stope DP06 caved a number of levels above its design, generating large amounts of seismicity. Approximate $56 \%$ of all seismicity, Figure 8 , has occurred within D-block, with around 200 events greater than $0.5 \mathrm{M}_{\mathrm{L}}$ and $50 \%$ of all damaging events. 


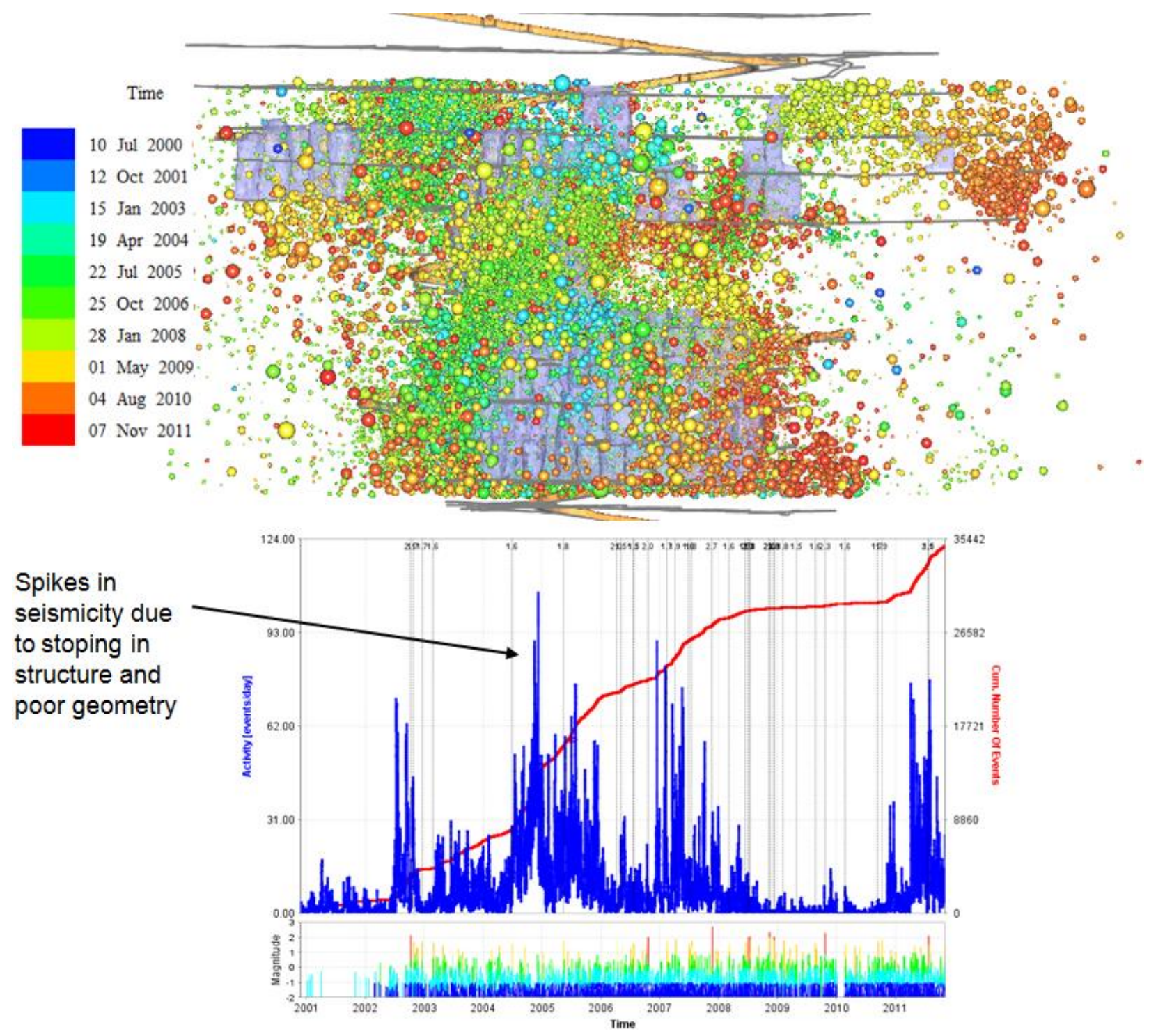

Figure 8 Seismicity in D-block

\section{3 E-block Upper}

E-block commenced development in October 2005 from 1,010 to 1,115 m, (9245RL). Stoping commenced in July 2007. Stopes are typically $15 \mathrm{~m}$ along strike and 30 to $60 \mathrm{~m}$ high. The ore thickness is 15 to $25 \mathrm{~m}$ resulting in stopes again being divided into panels from the HW to FW where applicable. E-block has had a far better success in managing seismicity during development. The ore drives have been stepped away from the Fitzroy fault by $5 \mathrm{~m}$ at the shoulder, this has reduced the initiation of cross cutting fault movement by the Fitzroy fault.

Only a few events have caused significant damage. This occurred as the stoping span reached around $120 \mathrm{~m}$ on strike. One event at the western abutment resulted in failure between the ore drive and footwall drive. This was a typical example of the footwall drive being brought too close to the orebody, creating a small pillar. As a result pillar dimensions for development have been reviewed. Upper E-block accounts for $14 \%$ of all seismicity, Figure 9, which at this stage is significantly lower than for D-block. 


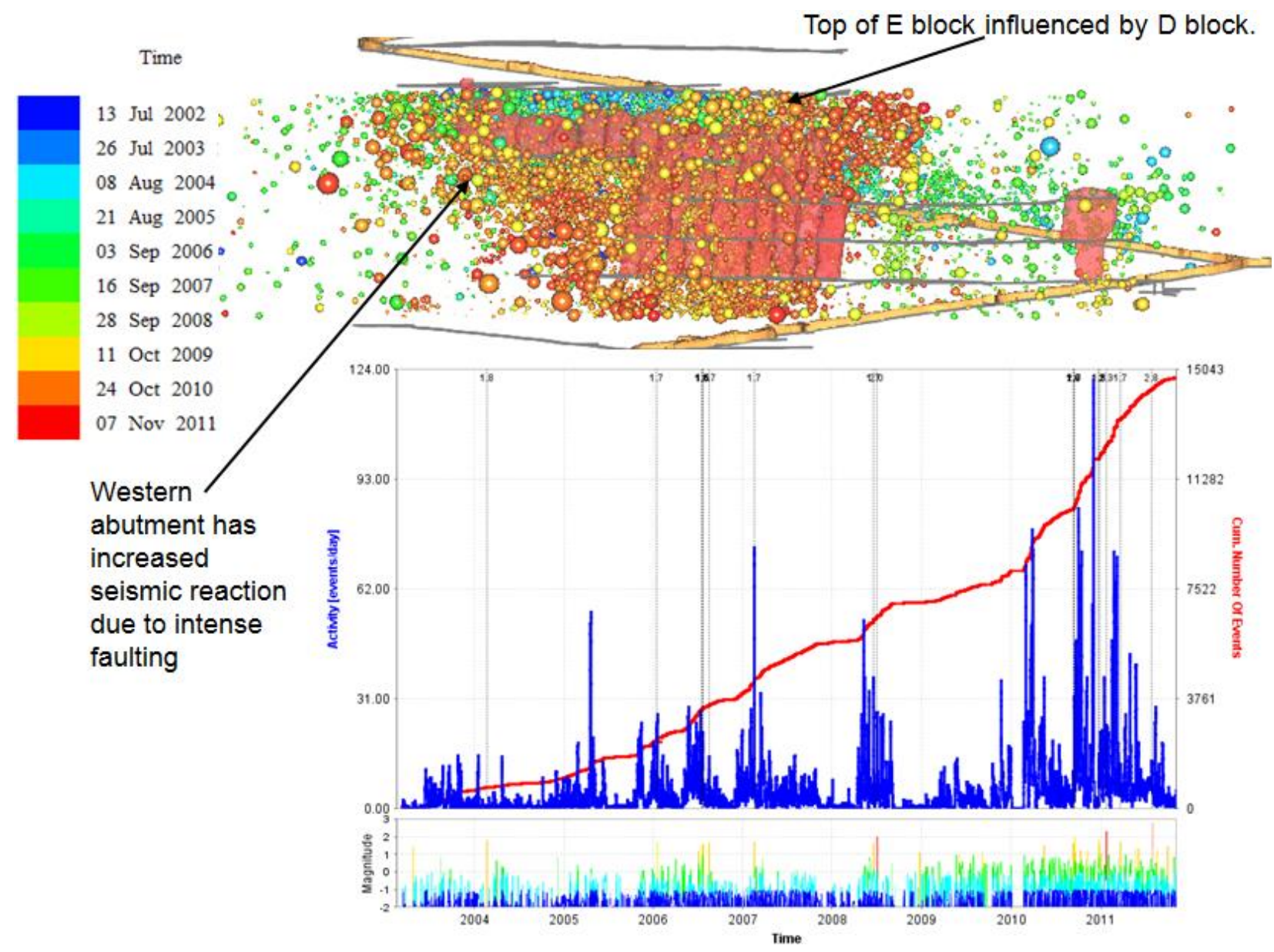

Figure 9 Seismicity in E-block upper

\section{4 Lower E-block}

Lower E-block, from 1,115 to $1,270 \mathrm{~m}$, (9090RL), is not yet in stope production but development has already experienced several damaging rockbursts, including four face bursts. The seismic risk during the development phase was anticipated and several measures put in place to manage this risk during the development phase. Figure 10 shows that lower E-block has accounted for $8 \%$ of all events to date. This is high considering stoping has not yet commenced. Stopes will typically be $15 \mathrm{~m}$ along strike and either single or double $30 \mathrm{~m}$ lifts. Several stoping sequences were analysed (non-linear modelling, Abaqus ${ }^{\circledR}$ ) to optimise the sequence, compare the seismic reaction and assist with the identification of at risk areas. Continuous mining fronts will be used with paste fill. No in-stope pillars will be left, which will mean some low grade stopes will have to be mined to ensure the sequence is maintained and no high stress pillars are formed. Two very low grade but large regional pillars will be left: Firstly a sill pillar between E-block and lower E-block, this pillar will be 45 to $65 \mathrm{~m}$ in height. The second is a pillar between the central/eastern block and the western block with a pillar strike span of $60 \mathrm{~m}$. Figure 11 shows the pillar locations.

Seismic activity over the last two years confirmed the importance of management of seismicity at Kanowna Belle which resulted in the initiation of further measures in seismic risk management. Again these are proactive measures initiated due to the early identification of the changes in seismic behaviour and associated risks. Some of these measures are described in more detail in later sections of this paper; but include face meshing, increase in dynamic support and additional procedures to manage exposure risk. 


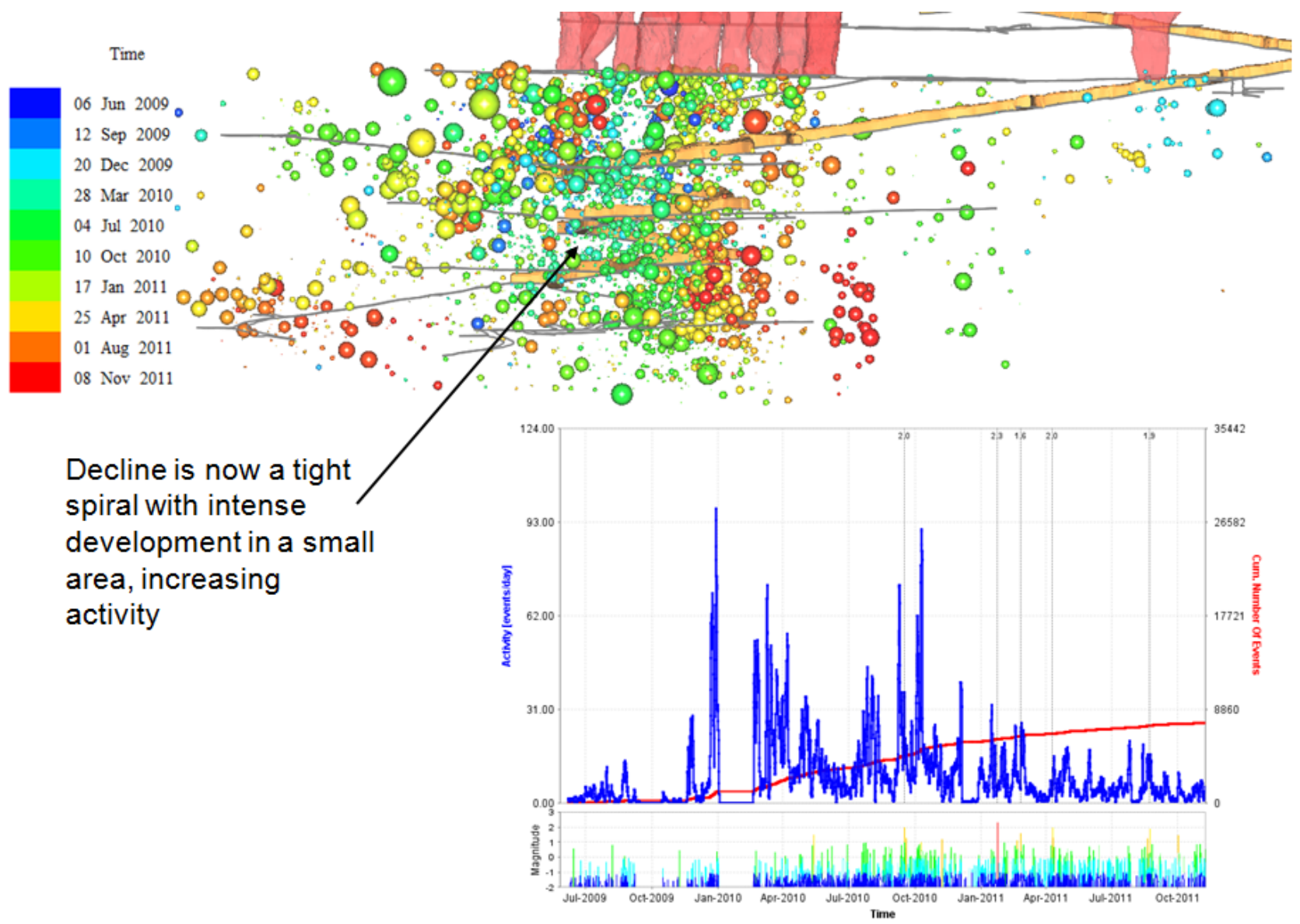

Figure 10 Seismicity in lower E-block

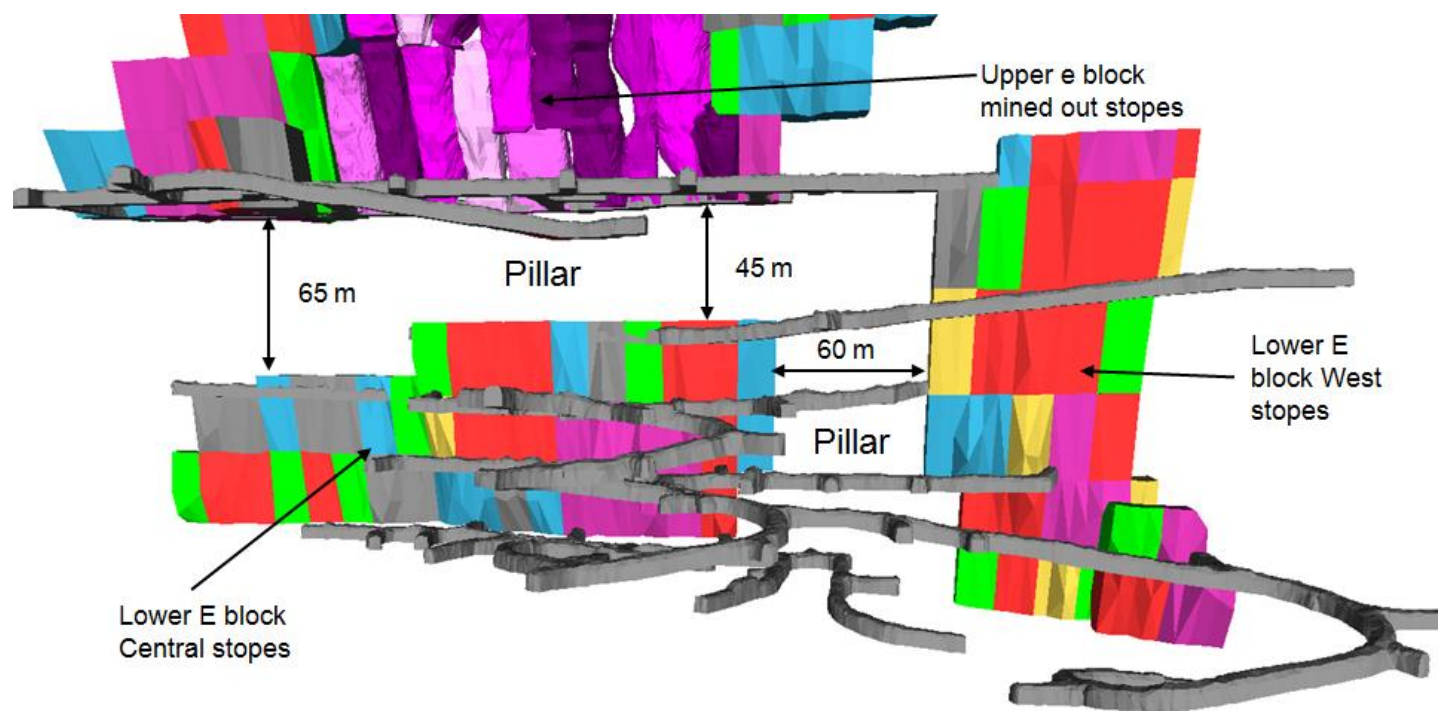

Figure 11 Lower E-block regional pillar location and size

\section{$4 \quad$ Failure mechanisms}

The failure mechanisms at Kanowna Belle are complex, but are typically fault-slip. The ratio of S-wave Energy to P-wave Energy of the seismic event indicates a shear mechanism of the structures present.

Seismicity is mostly associated with structures (Varden, 2009b). The position of major structures and lithological contacts are known and seismicity clusters locate consistently along these structures. Unknown structures are sometimes identified through clustering of seismic events on the fault contact. Seismic 
events associated with structures are usually greater than -0.5 local, (IMS) magnitude. The Fitzroy fault is the dominant structure of the mine. The fault is gouge filled and is a weak structure that slips easily allowing stress release with low levels of seismic occurrence. The Fitzroy fault is orientated approximately $30^{\circ}$ off the major principle stress direction.

One of the mechanisms is for the Fitzroy fault to deform-slip, which may then also initiate movement on other structures. Some of these are near parallel to the stress field resulting in more significant seismic events, sometimes resulting in damage. Floor heave is a common characteristic of large events at Kanowna Belle, along with bulking of the sidewalls and backs. Where support fails, there is often evidence of ejection from the sidewalls.

Specific failure mechanisms, determined from back analysis and observations are:

1. Fault slip.

2. Reverse fault slip.

3. Strainbursts (development).

4. Dynamic pillar failures.

5. Seismic shake down - generally occurs some distance away from the event and is mainly associated with older areas which are now de-stressed and the support is either old or at a different standard used in new development in similar environments.

\section{$5 \quad$ Future seismic risks}

Above all, the safety of personnel is of upmost importance. Systems and procedures are in place to manage and reduce the risk to personnel associated with seismicity. A significant issue to operating the mine is the concerns and perceptions of personnel regarding seismicity. Good communication, training and participation are of utmost importance.

Figure 12 below shows D- and E-block with results from Abacus numerical modelling - numbers on the figure relate to specific items - D-block west, sill pillar, western pillar and western block, decline and escape ways.

Kanowna Belle is a mature mine. The extent of the mined out volume has reached an extent where seismicity is no longer only affecting local active mining areas, but changes in geometry now sometimes also affect areas further away. The seismic risk is generally spread across C-, D- and E-blocks. However, some of the identified higher risk areas include: D-block west (especially footwall accesses) and lower E-block. Other specific areas are the sill pillar between the base of E-block and the top of E-lower; the pillar between lower-E central and lower-E west; the main decline loops in the lower mine where it is intersected by structures; and the escape ways, orepasses and ventilation rises of the lower E-block.

These locations of elevated risk have been determined through seismic history and non-linear modelling. Specific management strategies for each area have or are in the process of being put in place. Figure 12, shows a view from non-linear modelling that demonstrates the consequences of stresses as lower E-block is extracted. High stress levels are developed that mobilise the cross cutting structures. Where these structures intersect infrastructure and development drives, additional ground support will be installed and Seismic Risk Management (SRM) strategies put in place.

Guttenberg-Richter analysis was done for D-, E- and lower E-block, indicating the potential magnitude of events for each of the blocks. D-block currently has been identified as an area of increased risk, based on historical data, extensive fracturing/failure around older drives, and adverse cross-cutting structures in D-block west.

Extensive stoping in the lower E-block has not yet started, but seismic data analysis, non-linear numerical modelling, presence of several faults, and observed fault behaviour indicate that seismic events with damage potential will occur as mining progresses. Pro-active measures are taken to prepare the mine for 
this, and to manage the risk associated with this seismicity. Work is being carried out to identify the critical areas and increase support capacity and quality in these areas. Areas for possible redesign and redevelopment are identified and planned to be completed prior to stoping and associated seismic activity.

Note in Figure 12 below the stress change as mining spans increase and loading up of structures. Red indicates highest stress with increased risk of seismicity.

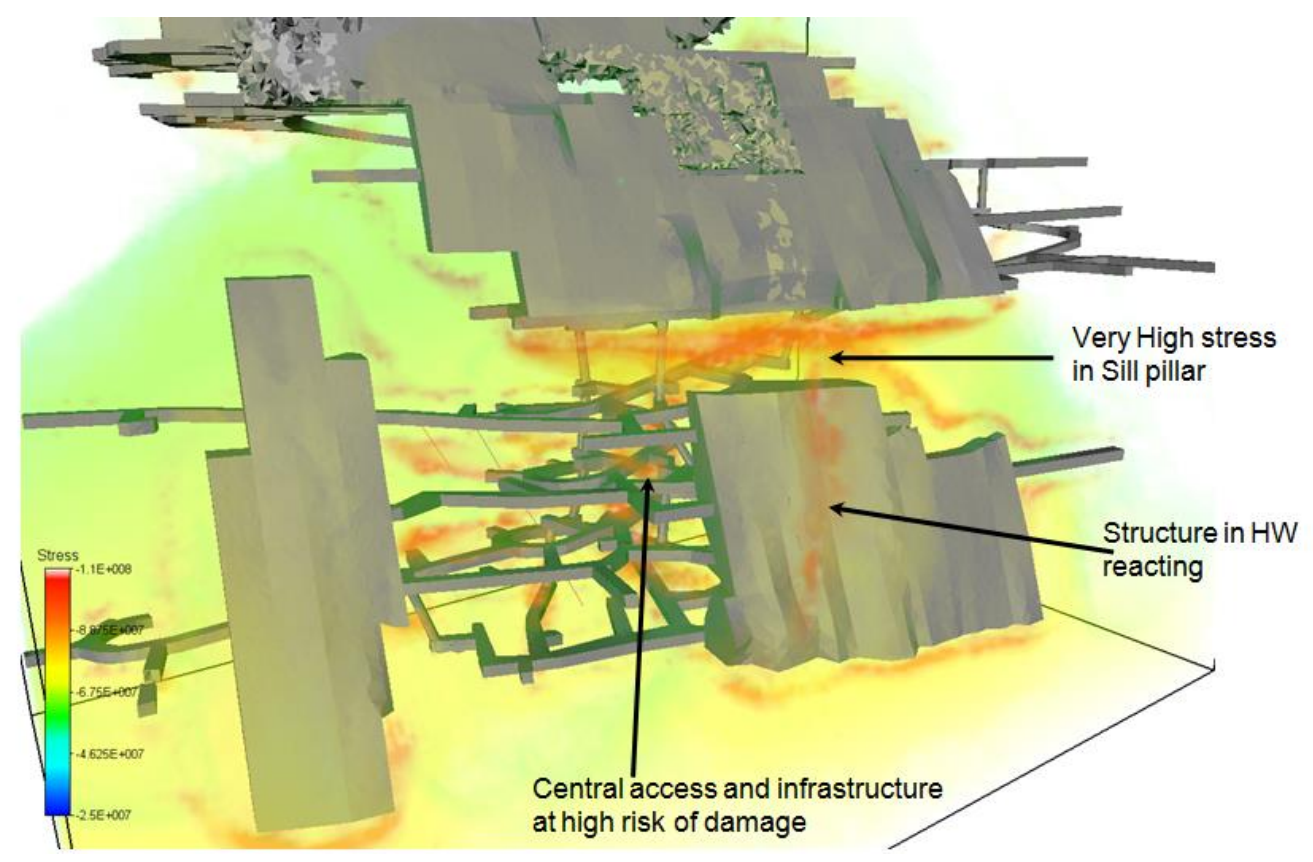

Figure 12 Non-linear modelling of lower E-block

\section{Seismic risk management systems and measures}

The Barrick Kanowna management has been very supportive and co-operative to the geotechnical department in managing the seismic risk. Seismic risk management (SRM) systems and measures include: management and work procedures, seismic monitoring and analysis, and ground support systems. Some of the systems in place to manage seismicity at Kanowna Belle are listed below:

- Ground control management plan.

- Seismic monitoring system.

- Analysis software and systems - JMTS, JDi, MSRAP.

- Numerical modelling.

- Seismic risk ranking and exclusion zones.

- Design procedures for development and stoping.

- Triggered action response procedures.

- Daily, weekly and monthly seismic reports.

- Ground support design - procedures and standards.

- QAQC management systems.

- Paste filling.

- Geotechnical staffing, inspections.

- Ground observation reports. 
Often conditions are conducive to the occurrence of increased seismicity at a mine. Analysing seismicity, and developing an understanding of the mechanism is important, but more critical is what you do regarding managing the risk of seismic impact. How do you 'live' with seismicity? It is very important to be pro-active, to anticipate future behaviour, and to be prepared to manage risks associated with this behaviour. All of these actions/efforts can be classified under three basic categories:

- Actions to reduce the frequency and magnitude of larger events impacting on excavations (design and sequence).

- Actions to identify elevated risk areas (where), and periods of elevated risk in the mining sequence (when).

- Actions to protect the work force from potential seismic impact.

The management of seismicity relies on a combination of control systems and analytical techniques. No one system can be used to manage the risk of seismicity. An important aspect of managing seismicity is mine design. Improved design to eliminate problem areas or situations is better than struggling to support and maintain safety in excavations in adverse seismic conditions. The design process involves data collection and analysis through to complex analytical techniques that result in hazard identification and quantification. Another important aspect in managing seismicity is adequate dynamic ground support. This needs to be viewed as a control on a local scale and may require maintenance over the life of a particular area.

Other SRM controls involve systems and procedures to remove personnel from the source of risk either on a temporary basis or permanently. Kanowna Belle has several SRM measures and systems in the ground control management plan, below is a summary of systems used and a short description of some of these systems.

\section{1 Mine design}

Mine design incorporates hazard identification, (rock mass behaviour including seismic risk), with subsequent application to development layout, stope design and stope sequencing. Some of the specific measures taken to improve development and stoping behaviour have been:

- Moving the hanging wall drive away from the Fitzroy fault, this has resulted in lower and less intense seismic events when cross cutting structures are intersected.

- Increased numerical modelling including non-linear Abaqus modelling, resulting in improved understanding of future behaviour, improved sequence decision making, and identification of increased risk areas.

- Use of photogrammetry to identify structures, allowing correct placement of intersections, improvement of stope design, improved numerical models and identification of risks associated with the structures.

- No pillars are left, i.e. total extraction, in some cases low grade stopes have to be extracted.

Based on the seismic hazard identification, investigations and past learning experience, a number of development and stope design, layout and sequence rules have been developed. Each stope has a specific stope design. This design is assessed geotechnically and recommendations made relating to seismic risk and dilution risk. Expected exclusion zones are given and reviewed when needed. The lower E-block, considering its anticipated seismic risk, has been extensively modelled and analysed to ensure a geotechnical optimized mining method and sequence are used. 


\section{2 Seismic hazard identification}

Seismic hazard identification consists of ranking the seismic risk against a set of criteria, these include: extraction sequence, stope and development geometry, structural interpretation, rock mass quality, stress analysis, installed ground support and seismic activity analysis.

Seismic analysis of active seismic clusters includes spatial and temporal distribution analysis to determine structural behaviour over time and its reaction to development and stope blasts. Time-history graph analysis is used to monitor and analyse for changes in seismic behaviour. The mine has introduced a Seismic Areas Monitoring System (SAMS), where seismic behaviour in areas of interest is monitored daily. Findings are recorded in a database, including SRM actions to be taken if needed.

\section{3 Numerical modelling}

Map3D elastic modelling is used for assessment of localised problems, to make quick comparisons of the effect of stope changes, and to back analyse seismic events. A mine scale Map3D model is used for stress input in to MSRAP software. Abacus non-linear modelling is used for sequence determination analysis work, identification of rock mass damage extent, and to determine the 'when' and 'wheres' of potential increased seismic risk. Figure 12 shows an example of Abacus modelling results displayed with Voxler viewer.

\section{4 Headings and stope risk ranking}

The seismic hazard identification leads on to risk ranking of development and stopes. The ranking is based on the following definitions of risk:

- Low seismic hazard: High probability that events may occur of less than -0.5 local magnitude within the time of the planned development and or stope extraction. No damage or deterioration is expected in this area.

- Moderate seismic hazard: A 40-60\% probability that events of greater than -0.5 , but smaller than 0.5 local magnitude may occur within the time of the planned development and or stope extraction. There is a low response in the area, no mapped structures, but possible structure exists. Low level of damage and or deterioration is expected.

- Medium seismic hazard: A $60-80 \%$ probability that events of greater than 0.5 local magnitude within the time of the planned development and or stope extraction may occur. Structures exist, but have a low level of seismicity associated with them, no significant events greater than 1 local magnitude have occurred. Some medium level of damage or deterioration may occur.

- High seismic hazard: An 80\% plus probability that events of greater than 1.5 local magnitude within the time of the planned development and or stope extraction may occur. Active structures are known to exist with a history of events greater than magnitude 1. Extensive rehabilitation has occurred and or is likely to be required from damage and deterioration.

- Extreme seismic hazard: Extensive damage and events greater than magnitude 2 have occurred in the past with extensive rock mass deterioration. Structures are highly active and have a large response to development/stoping. It may be that mining and further stope extraction will not be feasible in the future.

\section{5 Sequencing}

The mining sequence is geotechnically controlled. A number of rules have been developed and once the sequence has been set it cannot be changed unless a geotechnical study has been done to illustrate the benefits of the change. The main design principle is continuous retreat extraction. Essentially extraction is bottom up centre out; however, the lower E-block has been further analysed to improve rock mass reaction 
to the sequence. All voids are filled, mainly with paste fill, with some abutment stopes used as waste fill stopes.

\section{6 Support systems}

The use of dynamic ground support systems is one of the tools in managing the seismic risk and impact. Kanowna Belle has developed a number of support systems for varying ground conditions and seismic risk. Depending on seismic risk the following can be used: in-cycle fibrecrete, friction bolts in combination with mesh and fibrecrete, the Garford rockbolt in conjunction with high strength fibrecrete and mesh (extensively described in papers Varden et al. (2008), and Varden (2009a)), and Dynamic Garford cable bolts. Mesh placed over the fibrecrete is an important part of the system in some areas. During a significant seismic event the fibrecrete between bolts maybe ejected in small, but still potentially lethal lumps, mesh controls this ejection. In E-block all faces are meshed for face burst protection.

A further improvement action is to upgrade the cable bolt support throughout active mining areas to yielding cable bolts. Thicker gauge mesh straps will also be used in some areas to strengthen the screen support, especially the mesh overlaps. Another improvement is the change to $3 \times$ outer strand mesh to increase the strength of the mesh during loading and yielding.

\section{7 Headings seismic risk ranking system (HSRRS)}

On a weekly basis the geotechnical department will review seismicity, structure and rock mass conditions and issue a support code, risk rating and any specific instructions. For the high risk category, the procedure "Headings Seismic Risk Ranking System" is applied, this is shown in the Table 1.

This system was developed to manage seismic risk in active development headings. The system ranks all headings against factors present that may result in an increased seismic risk to the heading. Depending on the rating, certain actions are put in place. Headings are rated from a Level 1 to a Level 4 Rating. With a level 4 rating the heading is stopped, personnel are withdrawn from the area and a No Entry sign put in place until the area has been reviewed in detail. A specific action plan is then devised for this heading before work can continue in the heading.

Table 1 Risk ranking system for High Seismic Risk Ranking System (HSRRS)

\begin{tabular}{|c|c|c|c|c|}
\hline \multicolumn{5}{|c|}{ Fisk ranking } \\
\hline Area Damaged $20 \mathrm{~m}$ & No damage & Moderate damage & Medium damage & Significant damage \\
\hline & $\mathbf{0}$ & 1 & 2 & $\mathbf{3}$ \\
\hline \multirow[t]{2}{*}{ Structure with $\pm 5 \mathrm{~m}$} & No structure & $\begin{array}{l}\text { Structure within , no clusters } 1 \\
\text { no movement }\end{array}$ & $\begin{array}{l}\text { Structure with small } \\
\text { clustersiminor movement, } \\
\text { including past activity }\end{array}$ & $\begin{array}{c}\text { 1+ Structure with large } \\
\text { clusters' significant } \\
\text { movement, including past } \\
\text { activity }\end{array}$ \\
\hline & 1 & 3 & 5 & 7 \\
\hline \multirow[t]{2}{*}{ Events $>-0.320 \mathrm{~m}$} & 53 & 4 to 8 & 9 to 12 & 213 \\
\hline & 1 & 2 & 3 & 4 \\
\hline \multirow[t]{2}{*}{$\begin{array}{c}\text { Effect on levelivoid } \\
\text { abovelbelowiadjacent or } \\
\text { infrastructure }\end{array}$} & Not likely & Possible interaction & $\begin{array}{l}\text { Probable, it's a good } \\
\text { chance interaction will } \\
\text { occur or has occurred in a } \\
\text { similar geometry }\end{array}$ & \\
\hline & 1 & 2 & 3 & \\
\hline \multirow[t]{2}{*}{ Blast reaction } & $\begin{array}{l}\text { No structural response to blasting within } \\
\text { that heading }\end{array}$ & $\begin{array}{l}\text { Small structural response, } \\
\text { limited to that heading, event } \\
\text { s- } 0.3 \text { within } 3 \mathrm{hrs} \text { of blasting }\end{array}$ & $\begin{array}{c}\text { Significant structural } \\
\text { response, events }>-0.3 \\
\text { within } 3 \text { hrs of blasting }\end{array}$ & $\begin{array}{c}\text { Structural response }(>-0.3) \text { to } \\
\text { blasting on different level or } \\
\text { heading }\end{array}$ \\
\hline & -2 & -1 & $\mathbf{0}$ & 1 \\
\hline \multirow[t]{2}{*}{ Dynamic Support } & Dynamic bolts & No Dynamic bolts & & \\
\hline & 1 & 2 & & \\
\hline
\end{tabular}

\begin{tabular}{|l|l|l|}
\hline Ranking Scoring & Level & Required action \\
\hline 0 to 5 & Level 1 & No action continue as current controls adequate \\
\hline 6 to 11 & Level 2 & $\begin{array}{l}\text { Increased aw arenessirisk: Dperators to be informed, increased seismic and geotechnical } \\
\text { monitoring, shotcreting of face can be used as an additional control }\end{array}$ \\
\hline 12 to 15 & Level 3 & $\begin{array}{l}\text { Additional control measures to be applied: Minimum 3 hour exclusions, Increased } \\
\text { aw areness, review support - shotorete and mesh face - High Seismic Heading Control, } \\
\text { bogging, Adamtech and SiC no geotechnical control required }\end{array}$ \\
\hline 216 & Stop and Review - Potential for High Seismic Heading Control \\
\hline
\end{tabular}




\section{8 Exclusion zones}

Exclusion zones allow personnel to be removed from a specific area for a period of time in which the risk of significant seismicity is elevated. Exclusion zones are set based upon the seismic risk, modelling and history of the area. Exclusion times vary from one hour to 24 hours, with the most common time being three hours. Exclusion zones are typically applied to stope firings, but with the elevated risk in the lower mine are now starting to be applied to development headings firings.

Omori charts produced by MSRAP are the most common tool in determining exclusion times. Structure location, numerical modelling and historical seismic data are used in conjunction with the Omori charts to determine the extent of the exclusion zone.

\subsection{Mine control and ticker}

Kanowna Belle employs operators who are in charge of a mine control system. The mine control system is important in the seismic management of the mine. The IMS software utilises a program called Ticker, a web based system linked to the seismic controller underground. This allows operators to view events live. This allows the relay of information to geotechnical personnel when they are off site, and informing shiftbosses and foreman with regards to the location of events. The stand-by geotechnical engineer can make decisions whilst offsite using a laptop with full access to the seismic network, and mine data network, and all needed software. Ticker also allows the shift supervisor to make decisions regarding the evacuation of personnel from an area or from the mine, and to determine where to inspect following a seismic event.

\section{10 Reporting system for non-geotechnical personnel}

All underground personnel report ground movement occurrences, (includes noise, cracks opening up, falls of ground, support damage, water inflow), on a Ground Observation form. This form allows geotechnical engineers to investigate any ground movement or ground noise. Also, if the seismic system is down, or if there has been a significant event, the forms are used to gather data from personnel who may have damage information.

\section{11 Significant event control}

Two systems have been developed that are used as emergency control in the event of a significant event occurring underground. 1) Seismic Emergency Response Procedure and 2) Seismic System In-Operable Response Procedure. The second is required so personnel know the appropriate action to take when the system is down and no details are available. The principle of these procedures is to give information to the geotechnical engineer as fast as possible so that the geotechnical engineer can make informed decisions.

\section{12 Trigger action response plan (TARP)}

TARP's are used where normal procedures do not account for the unexpected. This includes meshing of faces where they are not standard procedures, inspection of the mine after significant seismic events, and when the seismic system is not operational.

\section{$7 \quad$ Educating and communicating with the work force}

Educating the workforce in ground control systems, seismic management and risk control is critical in managing the workforce and allowing them to have an understanding of the risks involved. Education involves two main sections, what they can do and what management/technical personnel are doing. It is important that the workforce gain confidence in management and geotechnical staff in order for them do their job safely and also give quality feedback to the geotechnical department.

Education of the workforce is accomplished in several ways:

- Inductions - site specific conditions and procedures. 
- Presentations at pre-start meetings and Tool Box meetings when changes are made to seismic management systems and when large seismic events occur.

- Geotechnical notice board - weekly seismic report, ground observation feedback and seismic event reports are placed on the notice board that is available to all personnel.

- Yearly ground awareness training.

- Informal interaction between geotechnical staff and workforce - this is mainly carried out by geotechnical staff talking to personnel underground during underground inspections.

At Kanowna Belle it is felt that there is a good relationship between the workforce and technical staff that has lead to a confidence in management systems, feedback from the operators and no injuries from ground movement incidents.

A daily seismic report of the last 24 hours is made at the morning production meeting; this includes number of events, largest events, location and any damage reports. A weekly seismic report is produced with details of where seismicity occurred around the mine in relation to development, stoping and filling operations. Additional information is added to with reference to a particular event(s) including damage, rehabilitation and information such as energy release. These reports are placed on an A0 plan and placed on the notice board so all personnel can view this information. Often placed on this plan is an educational section with information to improve workforce understanding of seismicity.

\section{Conclusions - summary of achievements and lessons learnt}

Kanowna Belle is a deep mine with regular large seismic events. The increased depth of mining, increased presence of adverse geological structures, and seismic event occurrence has increased the risks and challenges associated with seismic activity. Geotechnical management systems, mine management and the workforce are required to work closely to enable this risk to be managed in such a way that personnel are not injured or unnecessarily exposed to risks. This has been achieved at the mine over a number of years through the development of many management systems and with co-operation from the workforce.

Achievements made are:

- the introduction of dynamic support systems

- repositioning of ore drives

- numerical modelling of sequences

- increased knowledge and appreciation of seismic risk, and involvement of site management

- introduction of face meshing

- detailed seismic procedures

- high seismic risk heading control - improved confidence of contractors

- seismic area management system SAMS

- introduction of dynamic cable bolts

- reporting systems

- pre-conditioning trial

- a simple but sometimes under-estimated measure is the recent issue of new and faster geotechnical computers for increased work rate, job satisfaction and efficiency.

Due to the identified significant seismic risk, Kanowna Belle has embarked on a Geotechnical Action Plan during the last quarter of 2011 to further improve the quality of current systems and to introduce additional systems and measures. 


\section{Acknow l edgements}

The authors acknowledge Barrick Kanowna management for the support in being able to write this paper.

\section{References}

Varden, R., Lachenicht, R., Player, J., Thompson, A. and Villaescusa, E. (2008) Development and Implementation of the Garford Dynamic Bolt at Kanowna Belle Mine, in Proceedings 10th Underground Operators Conference, 14-16 April 2008, Launceston, Tasmania, Australian Institute of Mining and Metallurgy, pp. 95-102.

Varden, R. (2009a) Implementation of the Garford Dynamic bolt at Kanowna Belle Mine, in Proceedings 7th International Symposium on Rockburst and Seismicity in Mines, 21-23 August 2009, Dalian, China.

Varden, R. (2009b) Seismic management and seismic hazard quantification at Kanowna Belle Mine, in Proceedings 7th International Symposium on Rockburst and Seismicity in Mines, 21-23 August 2009, Dalian, China. 
